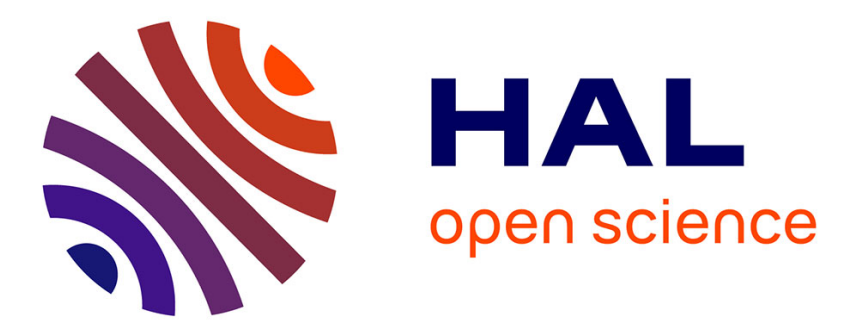

\title{
Iodine-Transfer Polymerization (ITP) of Ethylene and Copolymerization with Vinyl Acetate
}

\author{
A. Wolpers, F. Baffie, L. Verrieux, Lionel Perrin, Franck d'Agosto, Vincent \\ Monteil
}

\section{- To cite this version:}

A. Wolpers, F. Baffie, L. Verrieux, Lionel Perrin, Franck d'Agosto, et al.. Iodine-Transfer Polymerization (ITP) of Ethylene and Copolymerization with Vinyl Acetate. Angewandte Chemie International Edition, 2020, 59 (43), pp.19304-19310. 10.1002/anie.202008872 . hal-02972749

\author{
HAL Id: hal-02972749 \\ https://hal.science/hal-02972749
}

Submitted on 12 Nov 2020

HAL is a multi-disciplinary open access archive for the deposit and dissemination of scientific research documents, whether they are published or not. The documents may come from teaching and research institutions in France or abroad, or from public or private research centers.
L'archive ouverte pluridisciplinaire HAL, est destinée au dépôt et à la diffusion de documents scientifiques de niveau recherche, publiés ou non, émanant des établissements d'enseignement et de recherche français ou étrangers, des laboratoires publics ou privés. 


\title{
lodine-transfer polymerization (ITP) of ethylene and copolymerization with vinyl acetate
}

\author{
A. Wolpers,a F. Baffie,a L. Verrieux,b L. Perrin,b V. Monteil,a, ${ }^{*}$ F. D’Agostoa, ${ }^{*}$
}

\begin{abstract}
The first example of a controlled radical polymerization of ethylene using iodine transfer polymerization (ITP) is performed under mild conditions ( $\leq 100{ }^{\circ} \mathrm{C}$ and $\leq 200$ bar). Different commercially available, cheap, and non-toxic iodo alkyls (R-I) were used as chain-transfer agents (CTAs) in combination with 2,2'azobis(2-methylpropionitrile) (AIBN) to investigate the impact of the $\mathrm{R}$-group on the polymerization behaviour. These systems showed no rate retardation and no significant loss of chain ends. The formed well-defined end-capped polyethylene-iodine (PE-I) species is very stable upon storage. Narrow molar-mass distributions with dispersities around 1.6 were obtained up to number average molar masses $M_{\mathrm{n}}$ of $7300 \mathrm{~g} \mathrm{~mol}$-1. The copolymerization by ITP (ITcoP) of ethylene with vinyl acetate (VAc) to form poly(ethylene-co-vinyl acetate) (EVA) copolymer was also successful. By fine tuning the ethylene pressure and the vinyl acetate content, a broad range of copolymers containing from 0 to $85 \mathrm{~mol} \%$ of VAc unit was achieved. By reactivating the iodo chain-end, block copolymer structures composed of ethylene and VAc such as poly(ethylene-co-vinyl acetate)- $b$-polyethylene (EVA- $b$-PE) or gradient block copopolymers EVA- $b$-EVA with different content of VAc in the blocks were obtained for the first time using ITP. This highly versatile synthetic platform provides a straightforward access to a diverse range of well-defined PE based polymer materials. Finally, reactivity trends were explored by a theoretical mechanistic study.
\end{abstract}

\section{Introduction}

Reversible deactivation radical polymerization (RDRP) ${ }_{[1]}$ allows the synthesis of a wide variety of well-defined polymers.[2,3] After more than twenty five years of research and developments, a myriad of new polymer architectures and properties have been achieved. However, the RDRP of some monomers, sometimes of major industrial importance,[4-7] remains challenging. Among

Dr. A. Wolpers, F. Baffie, Dr. V. Monteil, Dr. F. D'Agosto,

Université de Lyon, Université Lyon 1, CPE Lyon, CNRS UMR 5265,

Laboratoire C2P2, Équipe LCPP, 69616 Villeurbanne, CEDEX, France

E-mail: vincent.monteil@univ-lyon1.fr franck.dagosto@univ-lyon1.fr

L. Verrieux, Dr. L. Perrin,

Université de Lyon, Université Claude Bernard Lyon 1, CPE Lyon, INSALyon, CNRS, UMR 5246, ICBMS, 43 Bd du 11 Novembre 1918, 69616

Villeurbanne, France

Supporting information for this article is given via a link at the end of the document. them is ethylene, which leads to polyethylene (PE), the most widely produced polymer in the world. While catalytic coordination-insertion and free radical polymerizations can industrially provide a variety of simple materials based on PE, complex macromolecular architectures from ethylene are difficult to obtain. Indeed, a new generation of sophisticated polyolefinbased materials is expected from the synthesis of chain-end functionalized PE and chain-end functionalized statistical or block copolymers of ethylene and polar vinyl monomers. After the development of ethylene radical polymerization under rather mild conditions $\left(<300\right.$ bar of ethylene pressure and $<100^{\circ} \mathrm{C}$ ), $[8,9]$ our group recently showed that RDRP based on reversible degenerative chain transfer (DT) (Scheme 1) is able to control the chain growth of PE. The first successful polymerizations of ethylene were reported using reversible addition-fragmentation chain transfer (RAFT) polymerization,[10,11] quickly followed by the use of organotellurium-mediated radical polymerization (TERP).[12] Yet, RAFT and TERP systems both suffered from a distinct side reaction of their intermediate radical species 1 in case of RAFT (Scheme 1a) and their transition state radical species 5 in case of TERP (Scheme 1b). PE. is a rather unstable radical species and thus in the DT main equilibrium of both systems, a competitive side fragmentation along the stabilizing $Z$ or $L$ group could be observed. It was especially pronounced when reversible chain transfer agents (CTA) containing alkyl stabilizing groups (e.g., $\mathrm{Z}=\mathrm{OEt}(\mathbf{2}), \mathrm{L}=\mathrm{CH}_{3}(\mathbf{6})$ ) were used. The reaction continuously decreased the livingness of the chains and impeded the use of chain end functionalities for further chemistry. Side-fragmentation could be reduced significantly when aromatic CTAs (e.g., $\mathrm{Z}=\mathrm{OPh}(3)$ or $\mathrm{N}\left(\mathrm{CH}_{3}\right) \mathrm{Ph}(4), \mathrm{L}=\mathrm{Ph}(7)$ ) were used. However, for the RAFT systems, this went along with rate retardation. Recently, in a more general study dedicated to the controlled copolymerization of ethylene and cyclic ketene acetal, the cobalt-mediated radical homopolymerization (CoMRP) of ethylene was reported to be controlled without any side reaction.[13] However, although very high amounts of the radical initiator AIBN were used, [AIBN]:[Coll CTA] $=6: 1$, only $0.52 \mathrm{~g}$ of PE could be obtained after $22 \mathrm{~h}$.

Another well-established RDRP technique based on DT is the iodine-transfer polymerization (ITP),[14-16] which requires the use of iodinated organic molecules that act as reversible CTAs (R-I in Scheme 1c). Considering the problems of the RAFT and TERP systems with side fragmentation at transition radicals 1 and 5, ITP seems an ideal candidate to be tested in ethylene polymerizations; as the ITP mechanism involves the transfer of one iodine atom only, reactions comparable to side 
fragmentation are theoretically impossible. In addition, the used iodo CTAs (presented below) combine many advantages over thiocarbonyl thio or organotellurium CTAs used in RAFT or TERP. Most of them are commercially available, cheap, and non-toxic. In addition, they are rather insensitive to air and ambient light, which allows for a convenient handling in the laboratory. The terminal iodine functionality offers many possibilities for further processing of the polymer, including various other polymerization techniques.[17-22] Most importantly for a monomer of industrial interest like ethylene, ITP is probably one of the very few RDRP that has already passed the test of industrialization for the polymerization of fluorinated monomers and acrylic acid.[23,24]

The systematic investigation of ITPs of ethylene will be presented in the present paper for the first time to our knowledge. The used iodo CTAs $(\mathrm{R}-\mathrm{I})$ are shown in Figure 1; they include species with a primary, a secondary, and a tertiary carbon attached to the iodine atom (CTA-1, CTA-2, and CTA-3, respectively) as well as the perfluorinated 1-iodohexane analogous (CTA-F). This allowed us to investigate the impact of the R-group on the polymerization behavior. Besides, poly(ethylene-co-VAc) is of high industrial importance as commercial additive.

(a) Degenerative chain transfer (DT) in RAFT polymerization (main equilibrium):

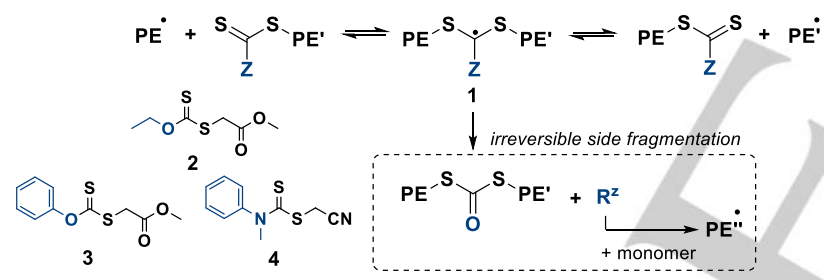

(b) Degenerative chain transfer (DT) in TERP (main equilibrium):

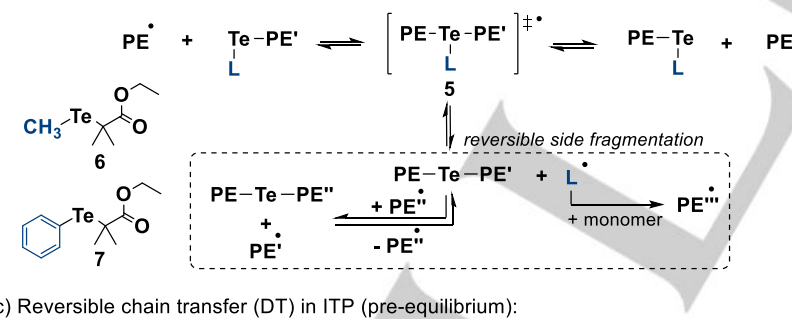

(c) Reversible chain transfer (DT) in ITP (pre-equilibrium):

$$
\begin{gathered}
\mathbf{P E}^{\cdot}+\mathbf{I}-\mathbf{R} \frac{k_{\mathrm{tr}}}{k_{\mathrm{tr}-1}} \mathrm{PE}-\mathbf{I}+\mathbf{R}^{\cdot} \\
\text { Degenerative chain transfer (DT) in ITP (main-equilibrium): } \\
\mathbf{P E}^{\cdot}+\mathrm{I}-\mathrm{PE}^{\prime} \frac{k_{\mathrm{tr}}}{k_{\mathrm{ex}-1}=k_{\mathrm{ex}}} \mathrm{PE}-\mathbf{I}+\mathbf{P E}^{\mathbf{i}}
\end{gathered}
$$

Scheme 1. Main equilibrium in both (a) RAFT and (b) TERP with the respectively observed side fragmentation for ethylene polymerization as well as (c) pre-equilibrium and main equilibrium in ITP.[10-12] PE and primed PEs represent different $\mathrm{PE}$ chains. $k_{\mathrm{tr}}, k_{\mathrm{tr}-1}, k_{\mathrm{ex}}$, and $k_{\text {ex }-1}$ represent reaction rate coefficients for iodine transfer.
They are industrially called VAE or EVA when their content in VAc is high and low, respectively. Considering the very limited amount of studies on controlling the architecture of EVA or $\mathrm{VAE}_{,[10,11,25-29]}$ a successful iodine transfer copolymerization (ITcoP) of ethylene and vinyl acetate (VAc) could lead to new, original, well-defined and most importantly easily accessible EVA and VAE. In addition to the homopolymerizations of ethylene, we thus investigated ITcoP of ethylene and VAc for a wide range of different monomer contents.

\section{Experimental Section}

The experimental setup and conditions used for the polymerization of ethylene are similar to our preceding works $[10,12]$ and briefly described in the following. In a typical procedure, the radical initiator 2,2'-azobis(2methylpropionitrile) (AIBN) and the CTA were stirred in $50 \mathrm{~mL}$ of dimethyl carbonate (DMC) in a $160 \mathrm{~mL}$ autoclave reactor at a constant temperature and ethylene pressure $\left(80-200 \mathrm{bar}, 60-80^{\circ} \mathrm{C}\right)$. The mixture was homogeneous and turned into a suspension upon formation of PE. (This could be observed with a similar type of reactor that was equipped with a sapphire window but not routinely used for polymerizations.) After a predetermined polymerization time, the reactor was cooled down, opened, and the contents were collected with either toluene or acetone. The polymer yield was determined gravimetrically after evaporation of the solvents. Copolymerizations of ethylene and VAc were conducted under similar conditions as the homopolymerizations of ethylene, using a CTA and AIBN. As the only difference, part of the DMC was replaced by VAc, so that the total liquid volume stayed at $50 \mathrm{~mL}$. The molar-mass distribution (MMD) of the resulting polymers was analyzed via sizeexclusion chromatography (SEC) either in THF at $40{ }^{\circ} \mathrm{C}$ (universal calibration with polystyrene) or in $1,2,4$-trichlorobenzene at $150{ }^{\circ} \mathrm{C}$ (conventional calibration with PE) if the product was not soluble in THF (for PE and EVA with \%VAc <10 mol\%). NMR spectroscopy was conducted in benzene-d6/tetrachloroethene, $1: 2$ by volume, at $90^{\circ} \mathrm{C}$ on a $400 \mathrm{MHz}$ spectrometer. Gas chromatography (GC) analyses were conducted on aliquots of the polymerization medium without further treatment using dodecane as internal standard. The set-up employed is a GC-FID (gas chromatography with a flame ionization detector) using an Agilent 6890HP-5 capillary column. The used substances, the experimental setup, polymerization procedure, and analytical methods are more thoroughly described in the Supporting Information.

\section{Results and Discussion}

ITP of ethylene 80 bar. Polymerizations were conducted in an autoclave at $70{ }^{\circ} \mathrm{C}$ and 80 bar of ethylene pressure using AIBN (50 mg, $6.09 \mathrm{mmol} \mathrm{L}-1$ ) and the iodo CTAs presented in Figure (18.3 mmol L-1, with a concentration ratio between the CTA and AIBN, [CTA]:[AIBN], of $3: 1$ and between ethylene and the CTA, [ethylene]:[CTA], of $640: 1$ ) in $50 \mathrm{~mL}$ of the solvent dimethyl carbonate (DMC). Further details about the polymerization 
procedure are presented in the Supporting Information. Figure 1a shows the conversion of ethylene versus polymerization time for the respective systems in comparison to a conventional polymerization system without CTA. Rather fast polymerizations and high polymer yields are obtained, while no rate retardation was observed in comparison to the CTA-free conventional system, as opposed to previously investigated RAFT systems.[11] The corresponding molar-mass evolution, i.e., the numberaverage molar mass $M_{n}$ and dispersity $\oslash\left(=M_{w} / M_{n}\right.$ with the weight-average molar mass $M \mathrm{w}$ ), versus ethylene conversion is presented in Figure 1b (see Figures S1-S4 for corresponding molar-mass distributions (MMDs)). $\oplus$ values are low for RDRPs of ethylene approaching values between 1.5 and 1.7 for higher $M \mathrm{n}$. In agreement with the theory of RDRP, the general trend of $M_{n}$ values follows the expected linear one while $M_{n}$ values are rather close to the theoretical values already at the beginning of the polymerization. The most striking discrepancy can be seen for PE obtained from CTA-1, whose $M$ values show a significantly higher offset (between 1500 and $2000 \mathrm{~g} \mathrm{~mol}-1$ ). This indicates slower first deactivation of propagating PE. by CTA-1 in the pre-equilibrium compared to the other CTAs (see Figure 1c). As a consequence, CTA-1 should also be the most slowly consumed CTA which was confirmed by GC analysis (Figure S5). The general order was CTA-1 < CTA-2 < CTA-3 can be straightforwardly expected as (i) their steric strain and (ii) the stability of the respective $R_{\bullet}$ in the pre-equilibrium increases in the same order.[15,30]. The fact that CTA-F is consumed much faster than CTA-1 could also be anticipated, as in literature polymerizations of vinylidene fluoride (VDF) at $75^{\circ} \mathrm{C}$, the iodine transfer rate coefficient $k_{\text {tr }}$ (see Figure 1c) of a CTA with a CF2-I function was determined to be more than 20 times higher than the one of a comparable CTA with a $\mathrm{CH}_{2}-\mathrm{I}$ function.[31] The transfer constant $C_{\text {tr }}$ of a CTA can be calculated by comparing its consumption with the ethylene conversion corresponding to the generation of PE (see Supporting Information).[31,32]

In addition to $70^{\circ} \mathrm{C}, \quad C_{\text {tr }}$ values were determined for polymerizations at 60 and $80^{\circ} \mathrm{C}$, while the corresponding polymerization results are provided in Figures S8 and S9. Ctr values of 15.3, 13.4 and 11.6 were determined for CTA-1 and 61.0, 55.3 and 43.8 were obtained for CTA-2, at $60^{\circ} \mathrm{C}, 70^{\circ} \mathrm{C}$ and $80^{\circ} \mathrm{C}$, respectively (Table S1). CTA-3 and CTA-F were consumed too quickly for a reliable quantification. This reactivity trend is supported and discussed in light of energy barriers computed at the DFT level for CTA activation, chain exchange and monomer addition (see Supporting Information Tables S2S5). At all temperatures, the iodine transfer of CTA-2 is about four times faster than that of CTA-1, while both CTAs show the general trend of higher $C_{\text {tr }}$ at lower temperatures. CTA-1 can be regarded as a mimic of PE-I in terms of iodine transfer, as for both species, a primary carbon atom is attached to the iodine atom. As a result, the $C_{\text {tr }}$ value of CTA-1 can be considered as $C_{\text {ex }}$ of the general main equilibrium (Scheme 1c).[31] This indicates that an increasing rate of iodine transfer compared to propagation at lower temperatures is a general characteristic in ITPs of ethylene. Similar observations were made for ITP of styrene, where the $C_{\text {ex }}$ value increased from 3.6 to 4.2 when decreasing the temperature from 80 to $50^{\circ} \mathrm{C}$.[33] $C_{\text {ex }}$ values for ITPs of ethylene are the highest so far compared to ITPs of other monomers described in the literature - including 3.8 for St (at $70^{\circ} \mathrm{C}$ ),[33] 2.2 for methyl acrylate (at $70^{\circ} \mathrm{C}$ ),[17] 2.6 for methyl methacrylate (at $80^{\circ} \mathrm{C}$ ),[34] and 7.5 for VDF (at $\left.75^{\circ} \mathrm{C}\right)$ [31]. a)

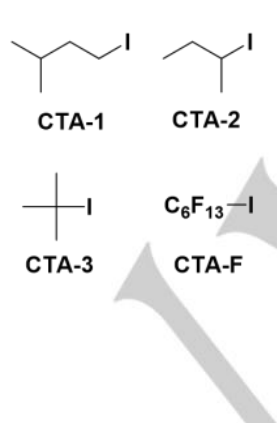

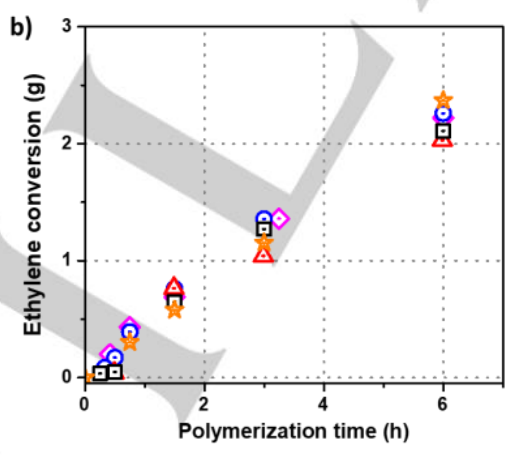

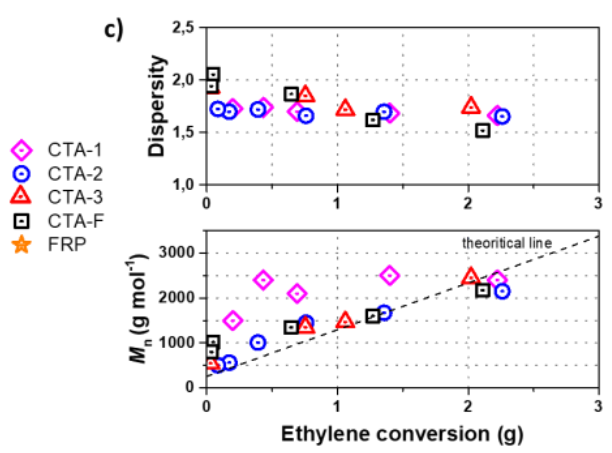

Figure 1. (a) Chemical structures of the used CTAs and (b) ethylene conversion versus polymerization time for ITP systems with the respectively presented CTAs compared to the conventional radical polymerization performed without CTA and (b) corresponding molar-mass evolutions (from SEC). The conventional radical polymerization yielded PE with $M \mathrm{n}$ values of about $8000 \mathrm{~g}$ mol- 1 and $\Theta$ values between 1.7 and 3.5. $T=70^{\circ} \mathrm{C}$, ethylene pressure $=80$ bar. 
Figure 2 shows an exemplary ${ }_{1} \mathrm{H}$ NMR spectrum of $\mathrm{PE}$ produced in the presence of CTA-F after $3 \mathrm{~h}$ (recorded at $90^{\circ} \mathrm{C}$ in the solvent system tetrachloroethylene (TCE)/ ${ }_{6} \mathrm{D}_{6} 2 / 1$ by volume). lodine end-capped PE is proven by the methylene protons adjacent to the iodine atom (triplet signal $d$ and quintet signal c). Comparison of the intensity of signal a from the methylene protons neighboring the R-group $\mathrm{C}_{6} \mathrm{~F}_{13}$ with the one of signal $\mathrm{d}$ indicates a loss of iodine chain-end functionality of about only $2 \%$ after $3 \mathrm{~h}$. For the other samples of the CTA-F mediated ethylene polymerization, $0 \%, 0 \%, 2 \%$, and $2 \%$ functionality loss was observed after $0.25 \mathrm{~h}, 0.5 \mathrm{~h}, 1.5 \mathrm{~h}$, and $6 \mathrm{~h}$, respectively. This illustrates successful ITP and a very high livingness of the produced PE chains. It is assumed that the small loss of functionality is mainly due to elimination of $\mathrm{HI}$ since weak signals between 4.5 and 6.0 ppm indicate the formation of a terminal double bond.[35] The presented calculation of livingness is not possible for PE from CTAs other than CTA-F as the signals stemming from protons neighboring the respective $\mathrm{R}$ groups are superimposed by the PE signals between 0.5 and $1.7 \mathrm{ppm}$ (Figure S10). Equally high percentages of chain-end functionality are nevertheless expected, as the R-groups are too far away from the iodine atoms to affect their reactivity toward degradation. The chain branching common in free radical polymerization of ethylene is represented by the presence of the signal at $0.8 \mathrm{ppm}$. It was quantified via ${ }_{13} \mathrm{C}$ NMR spectroscopy to approximately 6 branches per $1000 \mathrm{C}$ atoms (see Supporting Information Figure S11).[36] This held true for all PEs obtained from both ITP and FRP systems under our conditions, which shows that the ITP mechanism has no impact on the inherent branching in radical ethylene polymerization. This was expected as it was already observed for both the RAFT ${ }_{[10]}$ and TERP technique.[12]

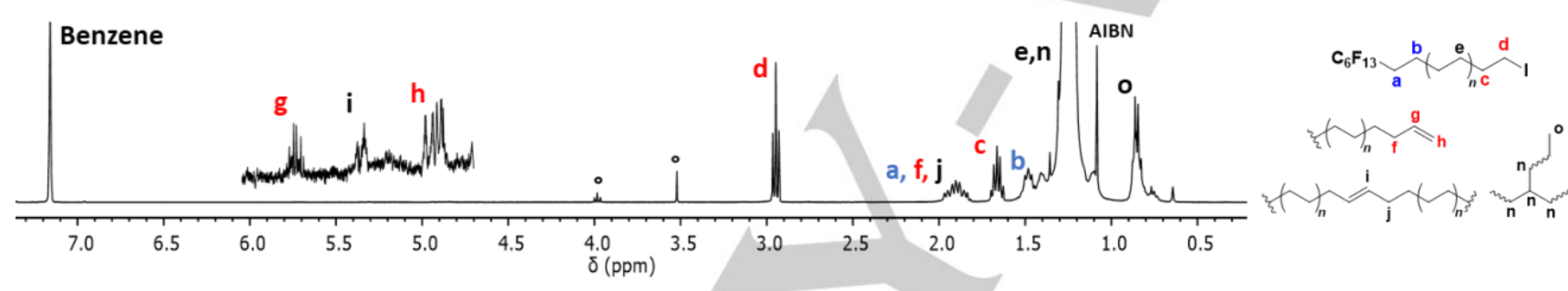

Figure 2. ${ }_{1} \mathrm{H}$ NMR spectrum (in TCE/C $6 \mathrm{D}_{6}$ at $90{ }^{\circ} \mathrm{C}$ ) of PE synthesized in the presence of $\mathbf{C T A}-\mathbf{F}$ (cf. Figure 1 , after $3 \mathrm{~h}$ ). The end group $-\mathrm{CH}_{3}$ stems from intramolecular chain transfer inherent in ethylene radical polymerization. *NMR solvent benzene, ${ }^{\circ}$ transfer to polymerization solvent DMC.As CTA-F exhibits one of the highest $C_{\mathrm{tr}}$ in homopolymerizations of ethylene and offers the possibility to see both extremities in NMR spectroscopy, we decided to further investigate the synthesis of higher molar mass PE using CTA-F.

ITP of ethylene 200 bar. To target PE with higher $M_{n}$ values along with higher yields via ITP, polymerizations were performed at 200 bar of ethylene pressure and at 90 or $100^{\circ} \mathrm{C}$ under otherwise identical conditions as presented above (Figure S12S14). For these elevated temperatures, the radical initiator was changed from AIBN to the more stable 1,1'-azobis(cyclohexane carbonitrile) (ACHN) to keep a radical production equivalent to the systems studied with AIBN at $70^{\circ} \mathrm{C}$.[37] $M \mathrm{n}$ values up to 7350 $\mathrm{g} \mathrm{mol}-1$ with $\Theta$ values between 1.5 and 1.6 were obtained. This illustrates the robustness of the polymerization and that relatively high $M_{\mathrm{n}}$ values can be achieved at high temperatures without compromising chain-growth control.

Copolymerizations of ethylene and VAC via ITcoP. As far as we are aware of, there is only one example of statistical copolymers of ethylene and VAc synthesized by ITcoP.[38] In this study, only EVAs with VAc contents of 40 mol\% were examined, which were synthesized in the presence of ethyl iodoacetate. Considering the good control observed for ITP of ethylene mediated by CTA-F, we anticipated that ITcoP might be a powerful tool to produce poly(ethylene-co-VAc) from low contents of VAc (EVAs) to high contents of VAc (VAEs). To screen the range of targetable VAc contents, copolymerizations were carried out with different quantities of VAc (replacing part of the solvent DMC, total volume $=50 \mathrm{~mL}$ ) and at different ethylene pressures at $70^{\circ} \mathrm{C}$. The corresponding experiments are presented in Table 1. Under the used conditions, the reactivity ratios are expected to be 1.16 for ethylene and 0.78 for VAc.[39] Both values are similar and close to unity, which leads to almost random copolymers. Computed energy barriers for monomer addition to each type of active chain end only differ by, at most, $0.6 \mathrm{kcal} \mathrm{mol}-1$. This supports reactivity ratios close to unity (Tables S6-S7). Entry 1 in Table 1 corresponds to the system with $5 \%$ of VAc in DMC (v/v) and 80 bar of ethylene after $6 \mathrm{~h}$ of polymerization. As shown in Figure S15, the MMDs of the same system obtained after $1.5 \mathrm{~h}, 3 \mathrm{~h}$, and $6 \mathrm{~h}$, which nicely shift toward higher molar masses upon polymerization.

${ }_{1} \mathrm{H}$ NMR analyses performed on the isolated polymers (Figure 3) showed that the expected resonances were observed and fully assigned to the respective protons. This absence of VAc terminal unit is noticed here as already described in the literature $[10,11]$ and further discussed below. The polymers' 
number-average molar masses, $M_{n, N M R}$, were calculated by comparing the integral of the resonance of the chain end protons $\left(-\mathrm{CH}_{2}-\mathrm{I}\right.$ at $\left.2.9 \mathrm{ppm}\right)$ and the resonances stemming from the polymer backbone $\left(-\mathrm{CH}_{2}-\mathrm{CH}_{2}-\right.$ at $0.8-2.1 \mathrm{ppm}\left(/_{1}\right)$ and $-\mathrm{CH}_{2} \mathrm{CH}(\mathrm{OAc})-$ at 4.6-5.1 ppm (/2)). Mn,NMR values were in good agreement with the number-average molar masses obtained by high temperature SEC (eluent trichlorobenzene at $150^{\circ} \mathrm{C}$, conventional calibration with PE), $M_{n, H T-S E C}$, for all samples analyzed. Considering their different solubility, copolymers with a VAc content of less than $10 \%$ were analyzed by hightemperature SEC, while for copolymers with higher VAc contents, THF-SEC (eluent THF at $40^{\circ} \mathrm{C}$, universal calibration with PS) was preferred. The method to determine the VAc content of the copolymer is described below. As a general remark, various copolymers with very different monomer contents were synthesized in the present work. Since different monomer contents might lead to different behaviors during an SEC experiment, we considered NMR spectroscopy as the more robust method for a quantitative comparison of the $M_{\mathrm{n}}$ values of the copolymers. Still, good agreement was observed between $M_{n, H T-S E C}$ or $M_{n}$,THF-SEC, $M_{n, N M R}$ and the expected $M_{n}$ values

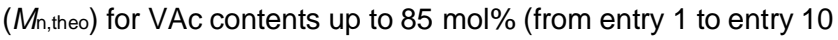
in Table 1). This supports that well-controlled copolymers with a high livingness of chains have been synthesized. The good control over chain growth already attested by Figure S15 for low content of VAc is further shown by an additional kinetics study performed for the system of entry $6(50 \% \mathrm{VAc}$ in DMC v/v). The results for different polymerization times are provided in Table S8. They again show good consistency between $\mathrm{Mn}_{\text {, theo, }} \mathrm{Mn}_{\mathrm{n}, \mathrm{HT}}$ $\mathrm{SEC}$, and $M \mathrm{n}, \mathrm{NMR}$ values with dispersities lower than 2 .

For entry 1 in Table 1, the VAc content was determined to be $4 \mathrm{~mol} \%$. It was increased up to $36 \mathrm{~mol} \%$ by increasing VAc/DMC to $75 / 25 \mathrm{v} / \mathrm{v}$ (entries 1 to 7 ). Copolymers with VAc contents up to $92 \mathrm{~mol} \%$ were further produced by reducing ethylene pressure down to 4 bar at a constant VAc/DMC of 75/25 v/v (entries 7 to 11). Keeping not less than $25 \%$ of $D M C$ in the starting polymerization medium was beneficial to avoid viscosity increase upon polymerization and thus guaranteed sufficient stirring throughout the polymerization. The presented experiments illustrate that the VAc content in the copolymers can simply be increased by increasing the amount of VAc before polymerization. That offers a convenient way to produce a broad range of copolymers with tunable thermal properties. This is exemplified by the data obtained from DSC analyses shown in Figure S16. Melting temperatures ranging from $115.8^{\circ} \mathrm{C}$ to $2.4^{\circ} \mathrm{C}$ and glass transition temperatures ranging from $-64.0^{\circ} \mathrm{C}$ to $35.6^{\circ} \mathrm{C}$ respectively for (co)polymers exhibiting VAc content ranging from $0 \mathrm{~mol} \%$ (i.e., $\mathrm{PE}$ ) to $85 \mathrm{~mol} \%$ were obtained.

${ }_{1} \mathrm{H}$ NMR spectra obtained for copolymers with VAc contents from 12 to $85 \mathrm{~mol} \%$ are presented in Figure S17. They all show a characteristic signal assigned to $\mathrm{CH}_{2}-\mathrm{I}$ at about $3.2 \mathrm{ppm}$ (spectra were measured in $\mathrm{CDCl}_{3}$, corresponding to $2.9 \mathrm{ppm}$ when the analysis is performed in $\mathrm{TCE} / \mathrm{C}_{6} \mathrm{D}_{6}$ like in Figure 3 ). This is because a terminal ethylene-iodine unit is less readily reactivated than a terminal VAc-iodine unit, so that the observation of a terminal ethylene-iodine unit is still more likely even for very high VAc contents. As a result, even for copolymers with high VAc contents up to $85 \mathrm{~mol} \%$, iodine chain ends are only connected to an ethylene unit rather than to a VAc unit. A similar behavior was seen when synthesizing EVA by RAFT.[10] It can be observed, however, that for increasing VAc contents (from 0 up to $85 \mathrm{~mol} \%$ ), the originally clean triplet at $3.2 \mathrm{ppm}$ gets superimposed by other triplets. This is assigned to the increasing probability of having penultimate VAc units, which affect the shift of the $\mathrm{CH}_{2}-\mathrm{I}$ protons of the terminal ethylene unit.

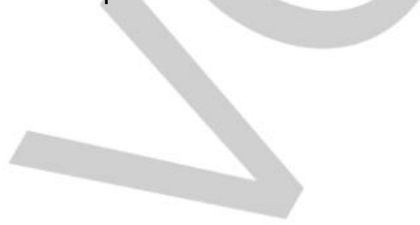

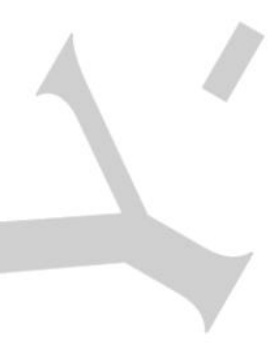


Table 1: ITcoPs of ethylene and VAc mediated by CTA-F.a

\begin{tabular}{|c|c|c|c|c|c|c|c|c|}
\hline Entry & $\begin{array}{l}\text { Ethylene } \\
\text { pressure } \\
\text { (bar) }\end{array}$ & $\begin{array}{l}\text { VAc } \\
(\%, \quad v / v \text { in } \\
\text { DMC) }\end{array}$ & $\begin{array}{l}\text { Monomer } \\
\text { conversion[b] } \\
\text { (g) }\end{array}$ & $\begin{array}{l}M \mathrm{n} \text { theo[c] } \\
(\mathrm{g} \text { mol-1) }\end{array}$ & $\begin{array}{l}M \mathrm{n} \mathrm{NMR[d]} \\
(\mathrm{g} \mathrm{mol}-1)\end{array}$ & $\begin{array}{l}M \mathrm{n} \mathrm{SEC}[\mathrm{e}] \\
(\mathrm{g} \mathrm{mol}-1)\end{array}$ & $\Theta_{[\mathrm{e}]}$ & $\begin{array}{l}\text { VAc content }[\text { ] } \\
(\mathrm{mol} \%)\end{array}$ \\
\hline $1_{[\mathrm{g}]}$ & 80 & 5 & 3.62 & 4350 & 4850 & 4650 & 1.57 & 4 \\
\hline $2[g]$ & 80 & 13 & 4.12 & 4800 & 5700 & 3950 & 1.56 & 9 \\
\hline $3[g]$ & 80 & 20 & 5.27 & 6100 & 7200 & 6300 & 1.63 & 12 \\
\hline 4 & 80 & 28 & 1.75 & 2300 & 3300 & 3450 & 1.78 & 16 \\
\hline 5 & 80 & 37 & 2.84 & 3400 & 4600 & 3950 & 1.89 & 22 \\
\hline $6_{[g]}$ & 80 & 50 & 13.10 & 14350 & 15150 & 12950 & 1.57 & 26 \\
\hline 7 & 80 & 75 & 4.37 & 4200 & 4600 & 4100 & 1.71 & 36 \\
\hline 8 & 60 & 75 & 7.15 & 8100 & 9300 & 8650 & 1.81 & 47 \\
\hline 9 & 40 & 75 & 14.83 & 15600 & 16200 & 15750 & 1.76 & 65 \\
\hline 10 & 15 & 75 & 24.03 & 25900 & 24900 & 26200 & 1.98 & 85 \\
\hline 11 & 4 & 75 & 2.88 & 3500 & 5800 & 5100 & 1.76 & 92 \\
\hline $12[\mathrm{~h}]$ & 80 & 28 & 2.73 & 1350 & 1400 & 2850 & 1.52 & 16 \\
\hline $13_{[i 4]}$ & 200 & 0 & $1.89 / 3.70[\mathrm{[}]$ & $\left.5500 / 9500_{[]}\right]$ & $6900 / 10700_{[]]}$ & - & - & $16-0[\mathrm{k}]$ \\
\hline $14_{[i]}$ & 80 & 50 & $2.60 / 8.78_{[i]}$ & 7050/20700[i] & $8400 / 22500_{[j]}$ & - & - & $16-26_{[k]}$ \\
\hline
\end{tabular}

[a] AIBN $(0.3 \mathrm{mmol}), \mathrm{CTA}(0.9 \mathrm{mmol})$ at $70^{\circ} \mathrm{C}$ in DMC (total volume $50 \mathrm{~mL}$ ) for more than $1.5 \mathrm{~h}$ of polymerization. [b] Monomer conversion $=(\mathrm{mass}$ of dried product) - (mass of AIBN) - (mass of CTA). [c] $M_{n}$ (theo) = (ethylene conversion [g]) / (CTA [mol]) + $M_{n}(\mathrm{CTA})$. [d] Calculated by comparing the ${ }_{1} \mathrm{H}$ NMR signals of the EVA chain and the iodo end-chain. [e] For polymer with VAc content lower than 10 mol \% determined by HT-SEC with conventional PE calibration. For polymer with higher VAc content determined by THF SEC with universal calibration. [f] Calculated by ${ }_{1} \mathrm{H}$ NMR by comparing the $\mathrm{CH}_{2}$ signals of the ethylene unit and the $\mathrm{CH}$ of the vinyl acetate unit. [g] $6 \mathrm{~h}$ of polymerization. [h] [CTA]/[AIBN] $=10 / 1$ and $2 \mathrm{~h}$ of polymerization [i] Chain extension of EVA from entry 12 at $80^{\circ} \mathrm{C}$. [j] after $2 / 6 \mathrm{~h}$ of reaction. [k] EVA content of the 1 st -2 nd block

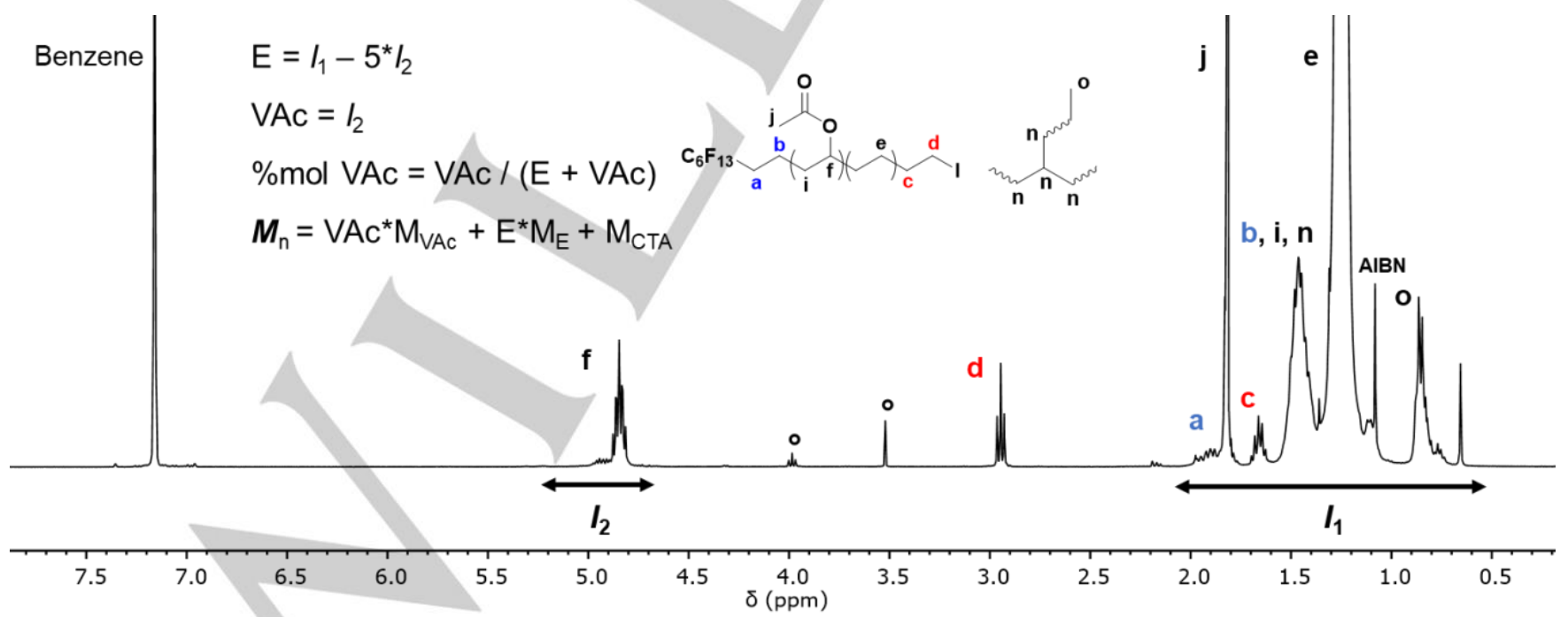

Figure 3. ${ }_{1} \mathrm{H}$ NMR spectrum (in TCE $/ \mathrm{C}_{6} \mathrm{D}_{6}$ at $90^{\circ} \mathrm{C}$ ) of an EVA obtained from ITcoP of ethylene and VAc mediated by $\mathbf{C T A}-\mathrm{F}$ at $70^{\circ} \mathrm{C}, 80$ bar of ethylene, and $\mathrm{VAc} / \mathrm{DMC}=5 / 95 \mathrm{~V} / \mathrm{V} \%$ after 6 hours of polymerization (entry 1 , Table 1 ). VAc content of the $\mathrm{EVA}=4 \mathrm{~mol} \%$. ${ }^{\circ}$ Transfer to polymerization solvent DMC. E and VAc are the number of ethylene and VAc units calculated by comparing the integral of the resonance of the chain end protons $\left(-\mathrm{CH}_{2}-\mathrm{I}\right.$ at $\left.2.9 \mathrm{ppm}\right)$ and the resonances from the polymer backbone $\left(-\mathrm{CH}_{2}-\mathrm{CH}_{2}-\right.$ at $0.8-2.1 \mathrm{ppm}\left(\mathrm{I}_{1}\right)$ and $-\mathrm{CH}_{2} \mathrm{CH}(\mathrm{OAc})-$ at $\left.4.6-5.1 \mathrm{ppm}\left(\mathrm{I}_{2}\right)\right)$. MvAc, ME, MctA are the molar masses of VAc, ethylene and CTA, respectively. 
For even higher VAc contents (92 mol\%, entry 11 ), the probability of having a VAc terminal unit is no longer negligible. In this case, the same chain-end degradation is observed as for ITPs of VAC alone: the formation of an aldehyde chain-end function and acetyl iodide (Figure S18).[40-42] The mechanism of chain-end degradation has been investigated via computional studies. The energy barrier remains high and the thermodynamics slightly endergonic, even if chain end is enriched in VAc units. However, both electrophilic and nucleophilic assistances allow to decrease the energy barrier by ca. $3 \mathrm{kcal} \mathrm{mol}-1$ (See Figure S19-S21 and Table S9). These interactions may depend on folding and chainend dynamics that both require intricate mechanistic investigations. As a conclusion, this effect determines the upper limit of the VAc content for copolymers of ethylene and VAc by ITcoP.

Block copolymerizations of ethylene and VAc via ITP. Block copolymerizations were thus conducted by chain extension of an EVA segment. For clarity sake, copolymers containing $X$ mol\% of $V A c$ are referred to as EVAx\% in the following. Chain extensions were performed with EVA $16 \%$ (synthesized in the system in entry 12) with ethylene or with ethylene and VAc targeting EVA $16 \%-b$ $P E$ and $E V A_{16 \%}-b-E V A_{26} \%$, respectively (entry 13 and 14 ). The corresponding SEC traces are presented in Figure S22 and a clear shift of the MMDs is observed in both cases indicating successful chain extension of the starting $E A_{16 \%}$. The corresponding ${ }_{1} \mathrm{H}$ NMR spectra recorded in $\mathrm{TCE} / \mathrm{C}_{6} \mathrm{D}_{6}$ as solvent are presented in Figure 4 and Figure S23. As the most striking effect, the distorted signal at ca $2.9 \mathrm{ppm}$ stemming from the terminal $\mathrm{CH}_{2}-\mathrm{I}$ in $\mathrm{EVA}_{16 \%}$ transforms into a clean triplet in Figure 4 when chain extension is performed with ethylene. This is consistent with the earlier explained effect that a penultimate VAc unit affects the chemical shift of the $\mathrm{CH}_{2}-\mathrm{I}$ protons and further confirms the installation of a PE segment on EVA $16 \%$ and the successful formation of EVA $16 \%$-b-PE. In contrast, consistent with a chain extension with $\mathrm{EVA}_{26 \%}$, a distorted signal can still be observed in Figure S23. Eventually, a good match between expected and experimental $M_{\mathrm{n}}$ values was observed after $6 \mathrm{~h}$ of reaction $\left(M_{\mathrm{n}, \mathrm{NMR}}=10700 \mathrm{~g} \mathrm{~mol}_{-1} \mathrm{vs}\right.$. $M_{\mathrm{n}}$ theo $=9500 \mathrm{~g} \mathrm{~mol}_{-1}$ and $M_{n, \mathrm{NMR}}=22150 \mathrm{~g} \mathrm{~mol}_{-1} \mathrm{vs} . \mathrm{Mn}_{\mathrm{n}}$ theo $=20700 \mathrm{~g} \mathrm{~mol}_{-1}$ for EVA $16 \%-b-\mathrm{PE}$ and $\mathrm{EVA}_{16 \%-b-\mathrm{EVA}} 26 \%$, respectively), although this agreement should be taken with care considering that these molar masses are not absolute values.

\section{Conclusion}

RDRP of ethylene was successfully performed for the first time by ITP in presence of various alkyl iodides used as CTA without any major side reaction. The impact of the structure of CTA on the generated PE was studied and the most promising one is CTA-F. It permits a high livingness from low molar mass up to $7350 \mathrm{~g} \mathrm{~mol}-1$, the highest reported so far for RDRP of ethylene.[10-12,25]

After polymerization, the formed end-capped polyethyleneiodine (PE-I) species is very stable upon storage. Further functionalization is thus possible by taking advantage of the reactivity of the iodine function. This includes chain-end conversion as well as further polymerization via ITP abut also potentially very promising alternative iodine-mediated polymerization techniques.[18,19,21,22]

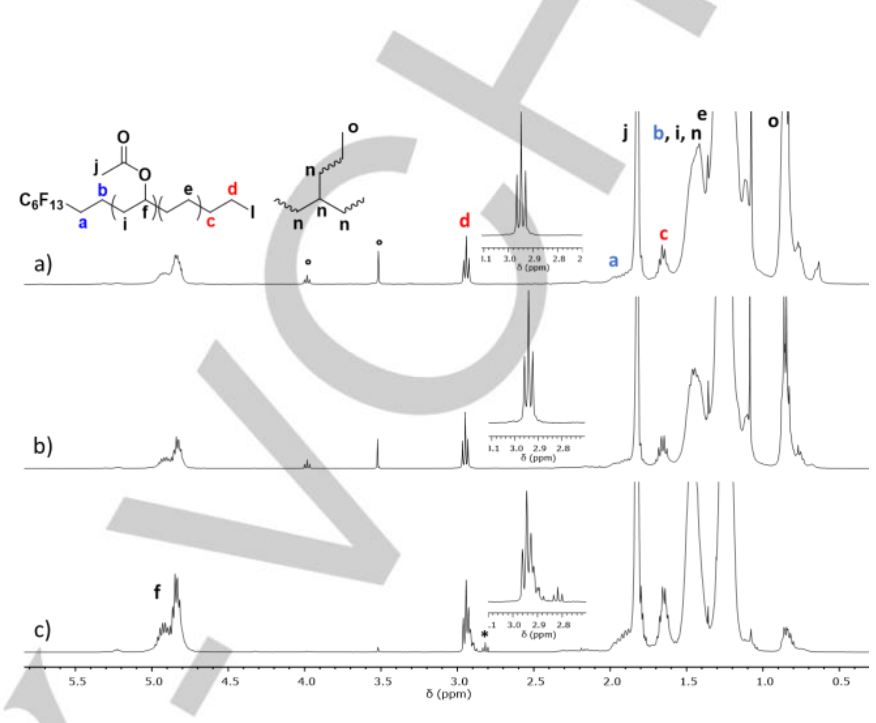

Figure 4. ${ }_{1} \mathrm{H}$ NMR spectra (in TCE/ $\mathrm{C}_{6} \mathrm{D}_{6}$ at $90^{\circ} \mathrm{C}$ ) of EVA $16 \%-b-\mathrm{PE}$ after after a) 6 hours and b) 2 hours chain extension and c) starting EVA $16 \%$. ${ }^{\circ}$ Transfer to polymerization solvent DMC. * Contamination from previous experiment.

Copolymerization of ethylene and vinyl acetate by ITP (ITcoP) is successful and gives access to a broad range of poly(ethyleneco-vinyl acetate) containing from of 0 to $85 \mathrm{~mol} \%$ of VAc. This highly versatile system provides a simple tool to an easy access to structures that are of original and potentially new alternative to EVA additives and related products intensively used in industry.

\section{Acknowledgements}

FB acknowledged the funding of the Ministère de l'Enseignement Supérieur, de la Recherche et de l'Innovation. Olivier Boyron and Manel Taam (C2P2) are acknowledged for their help with SEC analyses. Nicolas Foulon and Claude Bonura (CCIR, ICBMS) are acknowledged for providing computional technical support.

Keywords: polymerization $\cdot$ ethylene $\cdot$ iodine transfer polymerization (ITP) $\bullet$ vinyl acetate $\cdot$ copolymers

\section{References}

[1] A. D. Jenkins, R. G. Jones, G. Moad, Pure Appl. Chem. 2009, 82, 483-491.

[2] M. Destarac, Macromol. React. Eng. 2010, 4, 165-179.

[3] M. Destarac, Polym. Chem. 2018, 9, 4947-4967.

[4] M. Guerre, B. Campagne, O. Gimello, K. Parra, B. Ameduri, V. Ladmiral, Macromolecules 2015, 48, 7810-7822.

[5] S. Banerjee, V. Ladmiral, A. Debuigne, C. Detrembleur, R. Poli, B. Améduri, Angew. Chem. Int. Ed. 2018, 57, 2934-2937. 
[6] C. M. R. Abreu, A. C. Fonseca, N. M. P. Rocha, J. T. Guthrie, A. C. Serra, J. F. J. Coelho, Prog. Polym. Sci. 2018, 87, 34-69.

[7] C. M. R. Abreu, T. C. Rezende, A. C. Fonseca, T. Guliashvili, C. Bergerbit, F. D’Agosto, L.-J. Yu, A. C. Serra, M. L. Coote, J. F. J. Coelho, Macromolecules 2020, 53, 190-202.

[8] E. Grau, J.-P. Broyer, C. Boisson, R. Spitz, V. Monteil, Macromolecules 2009, 42, 7279-7281.

[9] E. Grau, J.-P. Broyer, C. Boisson, R. Spitz, V. Monteil, Polym. Chem. 2011, 2, 2328-2333.

[10] C. Dommanget, F. D'Agosto, V. Monteil, Angew. Chem. Int. Ed. 2014, 53, 6683-6686.

[11] A. Wolpers, C. Bergerbit, B. Ebeling, F. D’Agosto, V. Monteil, Angew. Chem. Int. Ed. 2019, 58, 14295-14302.

[12] Y. Nakamura, B. Ebeling, A. Wolpers, V. Monteil, F. D'Agosto, S. Yamago, Angew. Chem. Int. Ed. 2018, 57, 305-309.

[13] T. Zeng, W. You, G. Chen, X. Nie, Z. Zhang, L. Xia, C. Hong, C. Chen, Y. You, iScience 2020, 23, 100904.

[14] G. David, C. Boyer, J. Tonnar, B. Ameduri, P. Lacroix-Desmazes, B. Boutevin, Chem. Rev. 2006, 106, 3936-3962.

[15] P. Lacroix-Desmazes, J. Tonnar, in Polym. Sci. Compr. Ref. (Eds.: K. Matyjaszewski, M. Möller), Elsevier, Amsterdam, 2012, pp. 159-180.

[16] Y. Ni, L. Zhang, Z. Cheng, X. Zhu, Polym. Chem. 2019, 10, 25042515.

[17] P. Lacroix-Desmazes, R. Severac, B. Boutevin, Macromolecules 2005, 38, 6299-6309.

[18] A. Goto, H. Zushi, N. Hirai, T. Wakada, Y. Tsujii, T. Fukuda, J. Am. Chem. Soc. 2007, 129, 13347-13354.

[19] A. Goto, A. Ohtsuki, H. Ohfuji, M. Tanishima, H. Kaji, J. Am. Chem. Soc. 2013, 135, 11131-11139.

[20] A. Wolpers, P. Vana, Macromolecules 2014, 47, 954-963.

[21] F. di Lena, K. Matyjaszewski, Prog. Polym. Sci. 2010, 35, 9591021.

[22] M. Ciftci, S. Norsic, C. Boisson, F. D’Agosto, Y. Yagci, Macromol. Chem. Phys. 2015, 216, 958-963.

[23] H. Jager, Polyfluoroalkyl Iodides, Process for Their Manufacture, and Their Use, 1976.

[24] T. Miyajima, Y. Matsubara, H. Komatsu, M. Miyamoto, K. Suzuki, Polym. J. 2019, 1-9.

[25] A. Kermagoret, A. Debuigne, C. Jérôme, C. Detrembleur, Nat. Chem. 2014, 6, 179-187.

[26] J. Demarteau, A. Kermagoret, C. Jérôme, C. Detrembleur, A. Debuigne, in Control. Radic. Polym. Mater., American Chemical Society, 2015, pp. 47-61.

[27] J. Demarteau, P. B. V. Scholten, A. Kermagoret, J. De Winter, M. A. R. Meier, V. Monteil, A. Debuigne, C. Detrembleur, Macromolecules 2019, 52, 9053-9063.

[28] C. Detrembleur, J. Demarteau, A. Debuigne, A. Kermagoret, Block Copolymerization of Ethylene by Cobalt-Mediated Radical Polymerization, 2019, W02019121409 (A1).

[29] J. Demarteau, J. De Winter, C. Detrembleur, A. Debuigne, Polym. Chem. 2018, 9, 273-278.

[30] F. P. Lossing, G. P. Semeluk, Can. J. Chem. 1970, 48, 955-965.

[31] C. Boyer, D. Valade, P. Lacroix-Desmazes, B. Ameduri, B. Boutevin, J. Polym. Sci. Part Polym. Chem. 2006, 44, 57635777.

[32] S. G. Gaynor, J.-S. Wang, K. Matyjaszewski, Macromolecules 1995, 28, 8051-8056.

[33] A. Goto, K. Ohno, T. Fukuda, Macromolecules 1998, 31, 28092814.

[34] C. Boyer, P. Lacroix-Desmazes, J.-J. Robin, B. Boutevin, Macromolecules 2006, 39, 4044-4053.

[35] Y. He, X. Qiu, J. Klosin, R. Cong, G. R. Roof, D. Redwine, Macromolecules 2014, 47, 3782-3790.

[36] G. B. Galland, R. F. de Souza, R. S. Mauler, F. F. Nunes, Macromolecules 1999, 32, 1620-1625.
[37] J. Brandrup, E. H. Immergut, E. A. Grulke, Eds. , in Polym. Handb., Wiley, 2003.

[38] S. Borkar, A. Sen, J. Polym. Sci. Part Polym. Chem. 2005, 43, 3728-3736.

[39] A. Zarrouki, E. Espinosa, C. Boisson, V. Monteil, Macromolecules 2017, 50, 3516-3523.

[40] M. C. Iovu, K. Matyjaszewski, Macromolecules 2003, 36, 93469354.

[41] J. Tonnar, E. Pouget, P. Lacroix-Desmazes, B. Boutevin, Eur. Polym. J. 2008, 44, 318-328.

[42] H. Wang, F. Xu, K. Cui, H. Zhang, J. Huang, Q. Zhao, T. Jiang, Z. Ma, RSC Adv. 2017, 7, 42484-42490. 


\section{RESEARCH ARTICLE}

Controlled radical

polymerization of ethylene was conducted through ITP.

Coplymerization with vinyl acetate provides a range of well-defined structures, including poly(ethylene-co-vinyl acetate) containing VAc from 0 to $85 \mathrm{~mol} \%$.

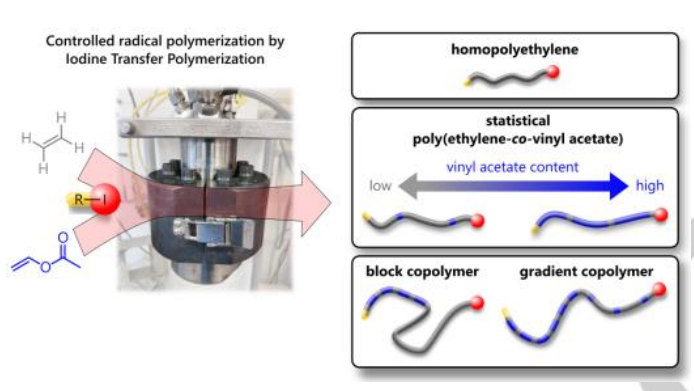

A. Wolpers, F. Baffie, L. Verrieux, L. Perrin, V. Monteil, ${ }^{*} F$. D'Agosto, *

Page No. - Page No.

lodine-transfer polymerization (ITP) of ethylene and copolymerization with vinyl acetate 